Revista do Departamento de Geografia
Universidade de São Paulo
www.revistas.usp.br/rdg

\title{
Estimativa de Perda de Solos por Erosão Laminar na Bacia Hidrográfica do Córrego Baguaçu-SP
}

\author{
Estimating Soil Loss by Sheet Erosion in the Basin of Córrego Baguaçu-SP
}

\author{
Laís Coêlho Do Nascimento Silva \\ Universidade de São Paulo \\ lais_cns@yahoo.com.br
}

\author{
Ailton Luchiari \\ Universidade de São Paulo \\ aluchiar@usp.br
}

Recebido (Received): 13/04/2016 DOI: $10.11606 /$ rdg.v2ii 0.114308

Aceito (Accepted): 16/08/2016

Resumo: A erosão é um fenômeno natural no modelado da superfície, no processo de remoção e de deposição de sedimentos, porém as atividades antrópicas, como o desmatamento, excedem os níveis naturais de perdas de solo. Para estimar a perda de solo anual em terrenos agricultáveis, existem modelos de predição que relacionam elementos físicos da paisagem junto às atividades antrópicas existentes. Nessa temática, o objetivo deste trabalho foi avaliar a perda de solos na Bacia Hidrográfica Córrego Baguaçu, localizada no oeste do estado de São Paulo, considerada uma região com processos de erosão acelerada. A Equação Universal de Perda de Solos (EUPS) permite avaliar o resultado dos produtos da erosividade da chuva, erodibilidade do solo, fator topográfico, cobertura do uso do solo, manejo e práticas conservacionistas, e que, aliados ao Sistema de Informação Geográfica (SIG), foi possível estimar espacialmente as áreas de maior vulnerabilidade à erosão, além de mapear feições lineares erosivas e apontar qual uso é mais responsável por grandes perdas de solos. Os resultados mostraram que grande parte da perda de solos na bacia concentra-se nas classes de perda de solo baixas (0 a 3 t/ha/ano), com predomínio das áreas ocupadas com pastagem e com cana-de-açúcar.

Palavras-Chave: Erosão Acelerada; EUPS; SIG.

\begin{abstract}
Erosion is a natural phenomenon in the modeled the surface removal process and sediment deposition, but human activities, such as deforestation, exceed natural levels of soil loss. To estimate the annual soil loss in arable land, there are models of prediction which relate to physical elements of the landscape with anthropogenic activities. On this subject, the aim of this study is to evaluate the loss of soils in the Baguaçu watershed, located in the west of the State of São Paulo, considered a region of intense accelerated erosion. The Universal Soil Loss Equation (USLE) allows you to evaluate the outcome of rainfall erosion index, soil erodibility, topographic factor, coverage of land use, management and conservation practices combined with the Geographical Information System (GIS), it was possible to estimate spatially the areas of greatest vulnerability to erosion, as well as linear features map changes and point out what is most responsible for heavy losses from soils. The results showed that much of the soil loss in the focuses on the classes of soil loss low (0 to 3 t/ha/yr), with predominance of the occupied areas with pasture and sugar cane.
\end{abstract}

Keywords: Accelerated Erosion; USLE; GIS. 


\section{INTRODUÇÃO}

Os processos erosivos têm sido assunto de grande preocupação na comunidade acadêmica, atentando sobre os recorrentes estudos acerca de toneladas de perdas de solos agricultáveis durante o ano e evidenciando as inúmeras formas erosivas, que se tornaram, em alguns locais, corriqueiras e triviais. As perdas são significativas e as consequências, muitas vezes, são irreparáveis, sendo que práticas conservacionistas de manejo adequadas seriam de grande ajuda para evitar que solos se tornem improdutivos futuramente.

O solo constitui-se de uma fina camada de material que recobre a superfície terrestre. Essa camada de material é resultante da desagregação de partículas de rochas, chamada de intemperismo, podendo ser de ordem física, química e/ou biológico, que geram camadas a que, tecnicamente, nomeiam-se horizontes. Assim, o solo é resultado da evolução que a rocha, exposta aos agentes intempéricos ao longo do tempo.

Tendo os solos essa origem, cabe afirmar que a erosão dos solos é um fenômeno natural, de caráter geológico, agindo na crosta terrestre como um processo benéfico para a renovação desses solos e a formação da sua diversidade (PRUSKI, 2009). Essa renovação e diversificação ocorrem de forma muito lenta, já que a cobertura natural (vegetação) protege cada horizonte, havendo um constante equilíbrio na formação do solo e no desgaste erosivo. Diferentemente, porém, a ação antrópica no meio ambiente acelera esse processo, em especial ao remover a vegetação natural. Havendo a remoção da vegetação, o solo fica desprovido de proteção, estando sujeito a fatores de depauperamento. Esse empobrecimento do solo vai depender da intensidade e da velocidade de degradação, fatores que variam de acordo com as próprias características de cada solo, além do clima, do relevo e da variedade de ações antrópicas praticadas (LEPSCH, 2011).

O solo é um recurso natural imprescindível para a manutenção e a sobrevivência da humanidade, e o uso por demais intensivo ou mesmo por demais extensivo, sem adoção de práticas conservacionistas, reduz ou faz perder a sua capacidade de produção de alimentos de origem vegetal, fator esse diretamente relacionado à escassez de alimentos e à fome (BERTONI e LOMBARDI NETO, 2012).

Outros problemas estão relacionados à erosão do solo, além da inutilização de áreas agricultáveis por motivo de erosão. Pode-se citar o assoreamento de canais de águas fluviais, a compactação dos solos, a remoção de nutrientes da camada superficial do solo e a poluição hídrica. São todos fatores que causam enormes prejuízos relacionados à perda de produtividade, a custos com corretivos e fertilizantes e à geração de energia para irrigação, entre outros fatores.

O uso de modelos preditivos de perda de solos por erosão e por deposição de sedimentos pelo uso agrícola, como, por exemplo, a Universal Soil Loss Equation (USLE), desenvolvida por Wischmeier e Smith (1978), é amplamente utilizada, seja em estudos aplicados a bacias hidrográficas ou a glebas experimentais. Aplicados em Sistemas de Informação Geográfica (SIG), representam uma ferramenta que permite a caracterização da paisagem, simulação dos processos e distribuição dos fenômenos (MITASOVA et al., 1997), consistindo numa forma prática de tomada de decisões, que visa minimizar os impactos gerados pela agricultura intensiva. Diante do exposto, o presente estudo tem como objetivo geral identificar áreas de maior susceptibilidade erosiva da Bacia Hidrográfica do Córrego Baguaçu, frente às mudanças agrícolas por que a bacia tem passado e quantificar a perda de solos atual na bacia, utilizando geotecnologias e modelo preditivo da Equação Universal de Perda de Solos (EUPS).

\section{ÁREA DE ESTUDO}

A Bacia do Córrego Baguaçu possui aproximadamente $614 \mathrm{~km}^{2}$ de área e uma extensão de $55 \mathrm{~km}$, desde a sua nascente até desaguar no Rio Tietê, no município de Araçatuba/SP. Está situada no Planalto Ocidental Paulista, que representa uma parcela expressiva da Bacia sedimentar do Paraná, ocupando aproximadamente 50\% do estado de São Paulo, cujas formações Serra Geral, Adamantina e Santo Anastácio compõem o Grupo Bauru na área de estudo (Figura 1).

A Geomorfologia da área, de maneira geral, constitui relevos de degradação: colinas amplas e médias, com longas encostas e baixas declividades. A Bacia do Córrego Baguaçu possui a cota mais alta das curvas de nível de $470 \mathrm{~m}$, e a mais baixa de $320 \mathrm{~m}$, ou seja, uma amplitude de $150 \mathrm{~m}$.

Segundo Sudo (1981), a litologia do Grupo Bauru é coberta por materiais arenosos e/ou arenosoargilosos de origem coluvial, que são depósitos cenozoicos ou formações superficiais terciárias/quaternárias. Esse material é responsável pela formação dos solos com B textural: Argissolos de Lins, variação Lins; e os solos com B latossólico: Latossolos Vermelho-Escuro, na fase arenosa. 
A área de estudo encontra-se localizada na região Aw, de acordo com a classificação de Köppen, com temperatura média entre $19^{\circ} \mathrm{C}$ a $28^{\circ} \mathrm{C}$ e estação seca no inverno. O período de chuvas se concentra anualmente nos meses de setembro a abril e o total de precipitação média mensal não ultrapassa os $250 \mathrm{~mm}$, e a precipitação média anual varia entre 1200 a $1500 \mathrm{~mm}$.

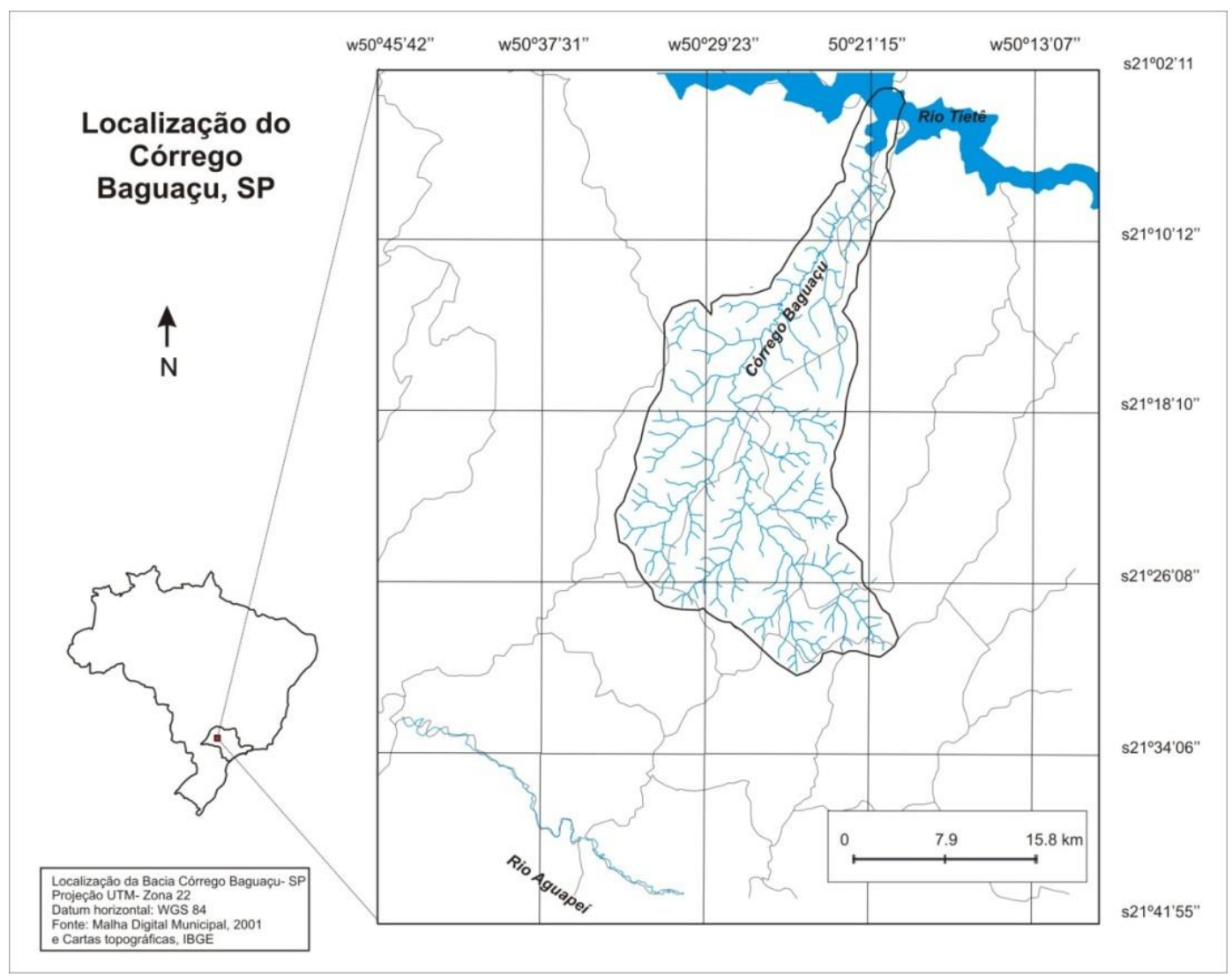

Figura 1: Mapa de localização da Bacia do Córrego Baguaçu.

\section{MATERIAIS E MÉTODOS}

A documentação cartográfica do Córrego Baguaçu consiste em mapas que representam os elementos físicos da área, tais como geologia, geomorfologia e pedologia, todos tirados dos relatórios da Unidade de Gerenciamento dos Recursos Hídricos (UGRHI 19), referentes à Bacia Hidrográfica do Baixo Rio Tietê, na escala 1:250.000 (CETEC, 1999). As bases digitais, como curvas de nível e rede de drenagem, foram obtidas com base nas cartas topográficas do Instituto Brasileiro de Geografia e Estatística (IBGE), na escala de 1:50.000, com equidistâncias das curvas de nível de 10 metros, sendo importadas para o software Spring 4.3.3, para posterior digitalização.

Os dados pluviométricos disponibilizados pelo Departamento de Águas e Energia Elétrica (DAEE) de 1971 a 2000 permitiram a análise de chuvas e erosividade, a partir de um posto com registros pluviométricos localizado no interior da Bacia do Córrego Baguaçu.

As fotografias ortorretificadas em formato GeoTiff, com resolução de 1 metro e escala de 1:25.000, do período de 2010/2011 (EMPLASA, 2010/2011), possibilitaram maior conhecimento dos tipos de uso e ocupação do solo existentes no período e as práticas conservacionistas, facilitando a sua quantificação e a espacialização.

\section{Fator Erosividade $(\boldsymbol{R})$}

Os índices de erosividade médios mensais foram obtidos por meio dos dados pluviométricos de 1971 a 2000, contando-se com os totais anuais e os valores médios mensais de precipitação local. Em alguns meses houve falhas nos valores mensais das chuvas, sendo as lacunas preenchidas com a média aritmética dos 30 anos do mês respectivo com falha. 
A falta de registro de dados gerados por pluviógrafos foi suprida com os dados de precipitação média mensal e média anual do município de Araçatuba/SP, utilizando a fórmula de Ei30 (Equação 1) do município de Votuporanga (COELHO, 2001). O índice de erosividade anual foi calculado por meio da soma dos valores mensais do índice de erosão (LOMBARDI NETO; MOLDENHAUER, 1992).

$$
\mathrm{EI}_{30}=-0,8804 \cdot \mathrm{R}_{\mathrm{c}}^{2}+65,4290 . \mathrm{R}_{\mathrm{c}}+62,9790 \quad \mathrm{r}=0,9915 ;(\mathrm{p}<0,01)
$$

\section{Equação 1}

Onde:

EI 30= índice de erosividade médio mensal; Rc= coeficiente de chuva (produto do quociente entre o quadrado da precipitação média mensal pela precipitação média anual); $\mathrm{p}=$ grau de liberdade.

\section{Fator Erodibilidade (K)}

Para determinar o fator K do Argissolo, foram utilizados, primeiro, o trabalho de Tavares (1986) na Bacia Hidrográfica do Rio São José dos Dourados, localizada a oeste do estado de São Paulo e, segundo, o trabalho de Mardegan (2012), que obteve resultados das amostras do Latossolo vermelho no município de Planalto/SP (Tabela 1). Por meio do conhecimento de algumas propriedades físicas e químicas dos solos da região, utilizou-se o método do nomograma de Wischmeier e Smith (1978) para a determinação do fator K do Argissolo variação Lins e do Latossolo vermelho.

Tabela 1 - Propriedades físicas e químicas dos solos presentes na Bacia do Córrego Baguaçu.

\begin{tabular}{cccccc}
\hline $\begin{array}{c}\text { Solos do Córrego } \\
\text { Baguaçu }\end{array}$ & $\begin{array}{c}\text { Matéria } \\
\text { orgânica (\%) }\end{array}$ & Areia (\%) & $\begin{array}{c}\text { Silte + areia } \\
\text { fina (\%) }\end{array}$ & Estrutura & Permeabilidade \\
\hline $\begin{array}{c}\text { Argissolo- } \\
\text { variação Lins }\end{array}$ & 1,5 & 61,2 & 36,1 & $\begin{array}{c}\text { Pequena } \\
\text { granular }\end{array}$ & $\begin{array}{c}\text { Moderada a } \\
\text { rápida }\end{array}$ \\
Latossolo vermelho & 1,3 & 41,4 & 37,5 & $\begin{array}{c}\text { Pequena } \\
\text { granular }\end{array}$ & $\begin{array}{c}\text { Moderada a } \\
\text { rápida }\end{array}$ \\
\hline
\end{tabular}

Fonte: Tavares (1987), Mardegan (2012) e Oliveira (1999).

\section{Fator Topográfico (LS)}

O fator topográfico (LS) é resultado da integração da declividade em porcentagem e o comprimento de rampa em metros (BERTONI e LOMBARDI NETO, 2012), conforme Equação 2

$$
\mathrm{LS}=0,00984 \mathrm{C}^{0,63} \mathrm{D}^{1,18} \text { Equação } 2
$$

Onde:

$\mathrm{LS}=$ Fator topográfico; $\mathrm{C}=$ Comprimento de rampa em metros; $\mathrm{D}=$ Grau de declive em porcentagem

Para determinar o comprimento de rampa foram necessários os vetores da linha de drenagem e os divisores de água das sub-bacias. Importou-se a drenagem como linhas de quebra e os divisores de água com valor $Z=0$, em um mesmo plano de informação, por meio da função mosaico. Com a função mapa de distâncias nas linhas de divisores de água foi criada uma grade com os valores de comprimento de rampa, conforme Tomazoni e Guimarães (2005); Souza (2010) e Ruthes et al. (2012).

A declividade (Fator S) foi fixada a partir das curvas de nível com equidistância de 10 metros e pontos cotados, informação essa obtida pelas cartas topográficas. Utilizando a programação "legal" do Spring, executou-se uma rotina para a criação da grade do fator topográfico (Fator LS), com auxílio da grade de declividade e da grade do comprimento de rampa.

\section{Uso e Manejo do Solo (C)}

A classificação das fotografias ortorretificadas foi feita por polígonos, de forma manual, analisando a imagem por meio de fotointerpretação e análise em campo, sendo que as classes de uso do solo, identificadas 
e existentes na Bacia do Córrego Baguaçu no ano de 2011, foram: solo exposto, cana-de-açúcar, culturas anuais, eucalipto, florestal, corpos d'água continentais, planícies de inundação, pastagem e áreas urbanizadas.

Para a determinação do Fator C foi utilizada a metodologia de Wischmeier e Smith (1978), sendo considerados os estágios de desenvolvimento das culturas, desde o preparo do solo para o cultivo da cultura até o período de colheita, atribuindo, para cada estágio, a razão de perda de solos para o manejo de tais culturas, conforme Carvalho (2012).

Os tipos de manejos para as culturas da bacia foram identificados como as mais usuais na região, sendo que, ao término dos cálculos do fator $\mathrm{C}$ definiu-se a média dos valores para as culturas e manejo da cana-de-açúcar, pastagem, o milho e soja (culturas anuais).

As culturas anuais são aquelas em que demoram um ano para completar seu ciclo, sendo consideradas na área de estudo apenas soja e milho, porque ocupavam maior área plantada no ano de 2011, segundo o IBGE (2012). Para a cana considerou-se o cultivo anual e cultivo de ano e meio sob preparo convencional, e a cana soca de ano e cana de ano e meio sem queima que foram consideradas no período de seis ciclos de cultivo. Para a pastagem avaliou-se dois sistemas de cultivo: o de plantio e o de cultivo do segundo ano em diante, num período de dez ciclos.

As culturas anuais (milho e soja) a pastagem e a cana são plantadas com início em setembro, pois é início das chuvas na região, possibilitando melhor desenvolvimento vegetal; o desenvolvimento da cultura é realizado em outubro, o plantio e estabelecimento em novembro e dezembro, e até agosto ocorre o crescimento e maturação. Considerou-se o ciclo de oito anos, que é o tempo necessário para a produção de celulose para o fator C do eucalipto, empregando a fórmula abaixo, de acordo com Martins (2005) (Equação 3)

$$
\mathrm{C}=\sum \frac{\mathrm{RPSi}}{\mathrm{Ri}} \quad \text { Equação } 3
$$

Onde:

C: é o fator cobertura do solo; I: estágio da cultura; RPS: Razão de perda de solo, R: erosividade da chuva.

O solo exposto recebeu valor de 1,0, de acordo com Vasquez-Fernandez et al. (1996) e a classe florestal de 0,0004 conforme Demarchi (2012).

\section{Prática Conservacionista $(\boldsymbol{P})$}

Por meio das fotografias ortorretificadas foi possível também visualizar áreas que possuem ou não alguma prática conservacionista, delimitando-as com polígonos na criação de um mapa temático, cujas classes foram divididas baseadas na classificação e valores empregados por Bertoni e Lombardi Neto (2012) para plantio morro abaixo de 1,0 e plantio em contorno de 0,5 .

\section{Estimativa de Perda de Solos}

O mapa de estimativa de perda de solos é resultado da integração dos fatores da EUPS anteriormente calculados, ou seja, a erosividade da chuva (R), erodibilidade do solo (K), fator topográfico do relevo (LS), uso e ocupação (C) e práticas conservacionistas (P) (Equação 4)

$$
\text { A= R. K. L. S. C. P Equação } 4
$$

Onde:

$\mathrm{A}=$ estimativa de perda de solo por unidade de área em tonelada por hectare ao ano (t/ha.ano);

$\mathrm{R}=$ fator erosividade da chuva em megajoule-milímetro por hectare-hora-ano (MJ.mm/ha.h.ano);

$\mathrm{K}=$ fator erodibilidade do solo em tonelada hectare-hora por hectare-megajoule-milímetro (t.ha.h/ha.MJ.mm);

$\mathrm{L}$ e $\mathrm{S}=$ fator variáveis fisiográficas do terreno, consideram a extensão da vertente (em metros) e da declividade (em \%) (adimensional);

$\mathrm{C}=$ fator de uso e manejo (adimensional),

$\mathrm{P}=$ fator práticas conservacionistas (adimensional).

Utilizando a ferramenta "legal" do Spring, relacionaram-se todos os fatores, conforme a equação: A= $\mathrm{R} * \mathrm{~K} * \mathrm{LS} * \mathrm{C} * \mathrm{P}$, por meio das grades com valores numéricos de cada fator, gerando uma grade final para fatiamento das classes de perdas de solo. 


\section{RESULTADOS E DISCUSSÃO}

\section{Fator $R$}

A precipitação média anual observada em Araçatuba é de 1.238,1 mm, com desvio padrão de 207,7 mm e erro padrão de $37,9 \mathrm{~mm}$ de média. O coeficiente de variação foi de $16,7 \%$. Com a distribuição de erosividade da chuva nos meses e nos anos para a série de dados de 1971 a 2000 de Araçatuba foi obtido o fator R de Araçatuba de 7.099 MJ.mm/ha.h.ano, com desvio padrão e erro padrão da média de 1.216 e 222 MJ.mm/ha.h.ano, respectivamente, com coeficiente de variação de $17,1 \%$.

Os valores extremos médios anuais de erosividade variaram de 4.150 a $9.632 \mathrm{MJ} . \mathrm{mm} / \mathrm{ha}$.h.ano e os índices de erosividade extremos mensais ocorreram nos meses julho e janeiro, com valores de 94 a 1.271 MJ.mm/ha.h.ano, respectivamente.

Por meio dos dados de erosividade mensal é possível identificar que há maior perda de solo por erosão entre os meses de outubro e março, pois $82,8 \%$ do índice de erosividade ocorreram nessa época, e menor perda de solos no semestre complementar, de 17,2\% (abril a setembro), assim como no trimestre de junho a agosto o valor foi de apenas $4,6 \%$.

As culturas cultivadas na bacia (cana de açúcar, milho e soja) são plantadas em setembro, ou seja, no início do período chuvoso, porém é necessária atenção quanto ao manejo nesse período, pois os preparos de solos, como o cultivo convencional, mobilizam a terra, deixando-a exposta a chuvas e enxurradas no período inicial em que a cultura não oferece proteção ao solo. As culturas de ano e meio, como a cana, é plantada no início de março, ou seja, quando o período de chuvas está terminando. Nesse período até a retomada das chuvas, deve-se oferecer proteção ao solo devido à erosão eólica, principalmente em solos arenosos, como é o caso do Argissolo.

\section{Fator $K$}

Os solos da Bacia do Córrego Baguaçu possuem forte gradiente textural entre os horizontes A e B, estando relacionados ao substrato geológico da Formação Adamantina, com camadas espessas de material de arenitos finos a muito finos em colinas médias e convexas. Os latossolos vermelhos estão dispostos em baixas declividades e encostas mais amplas, e os argissolos se encontram em relevos de maiores declividades e encostas com menores extensões (Figura 2).

Com os parâmetros estabelecidos, foram determinados os valores do Fator K, por meio do nomograma para o Latossolo vermelho, obtendo o resultado de $\mathrm{K}=0,027$ t.ha.h/ha.MJ.mm e, para os Argissolos, de $\mathrm{K}=$ 0,031 t.ha.h/ha.MJ.mm. Os resultados foram multiplicado por 0,1317 , para a conversão ao Sistema Internacional de Unidades, de acordo com Foster et al. (1981).

\section{Fator LS}

A maior área do Córrego Baguaçu é representada por colinas amplas, com topos extensos e vertentes de perfis retilíneos e convexos, apresentando declives suaves, com escoamento lento a médio, podendo ser adotadas práticas de controle da erosão, como terraços em nível e plantio em nível, entre outras. São áreas localizadas mais ao norte da bacia, próximas à foz.

De acordo com Lespch (2011), os argissolos, quando associados à latossolos, costumam se localizar em áreas mais declivosas. Na Figura 3 é possível visualizar essa afirmativa, onde a maior concentração de argissolos, cerca de $17,2 \%$ da bacia, está em declividades que variam de $6 \%$ a 12\%, e o latossolo vermelho concentra-se nas declividades mais baixas, de $0 \%$ a 3\%, com área de $24,7 \%$.

O comprimento de rampa com maior área de representatividade na Bacia do Córrego Baguaçu está entre as classes de 0 a $200 \mathrm{~m}$, com 32,7\% de sua área, seguindo-se com 28,4\% para a classe de comprimento de rampa entre 200 a 400 m (Figura 4). É possível notar que, nas áreas onde a declividade é maior (6\% a $12 \%$ ), o comprimento das encostas é menor e nas declividades mais baixas (0\% a 6\%), o comprimento de rampa possui maiores extensões, sendo isso visivelmente identificado nas áreas das nascentes e na foz da bacia.

O mapa de fator topográfico (LS) na Bacia do Córrego Baguaçu apresenta maior distribuição das áreas entre os valores baixos de dissecação do relevo (0 a 2) e distribuição dividida entre valores médios ( 2 a 4$)$ e altos de dissecação (>4) (Figura 5). A integração dos fatores L e S para a geração do Fator Topográfico da 
EUPS possibilita conhecer a influência da topografia na perda de solos, como no caso do Córrego Baguaçu que nas áreas mais íngremes (maior que 4) a velocidade do escoamento é mais rápida, e nas áreas de baixo fator topográfico ( 0 a 2 ) a declividade é baixa, porém o comprimento de rampa é maior, aumentando o volume de sedimentos transportados devido à distância.

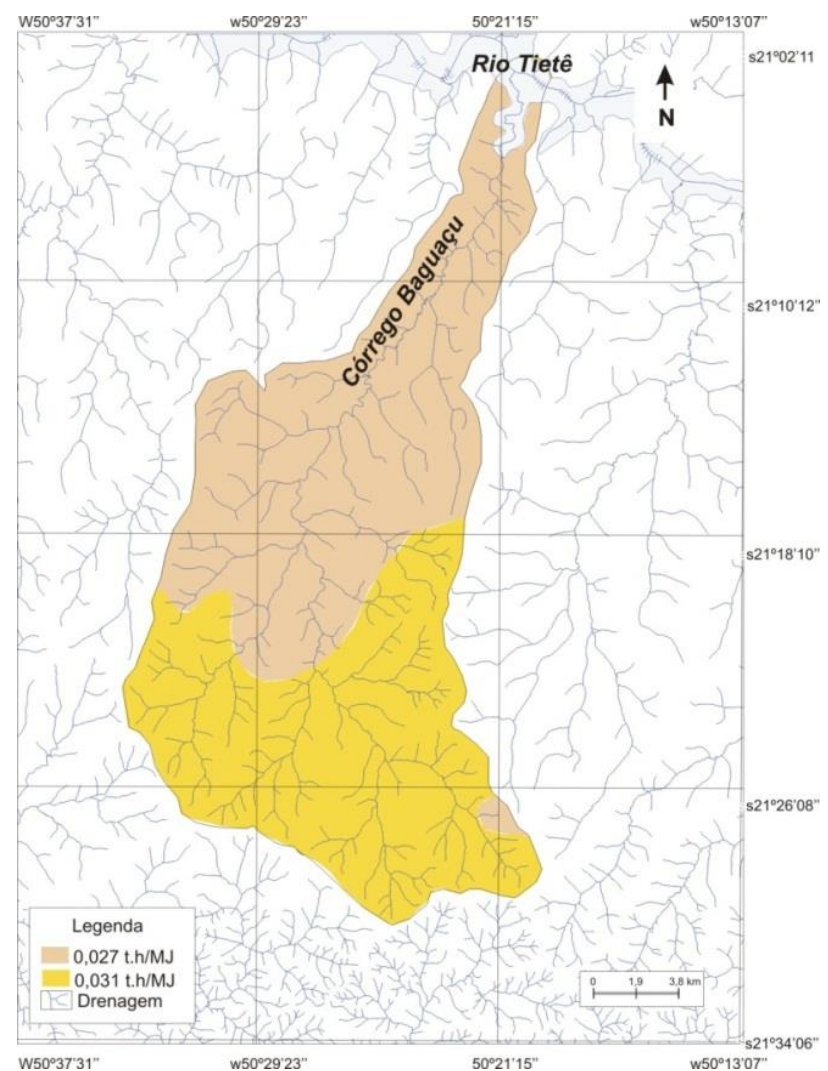

Figura 2: Fator K dos solos da Bacia do Córrego Baguaçu.

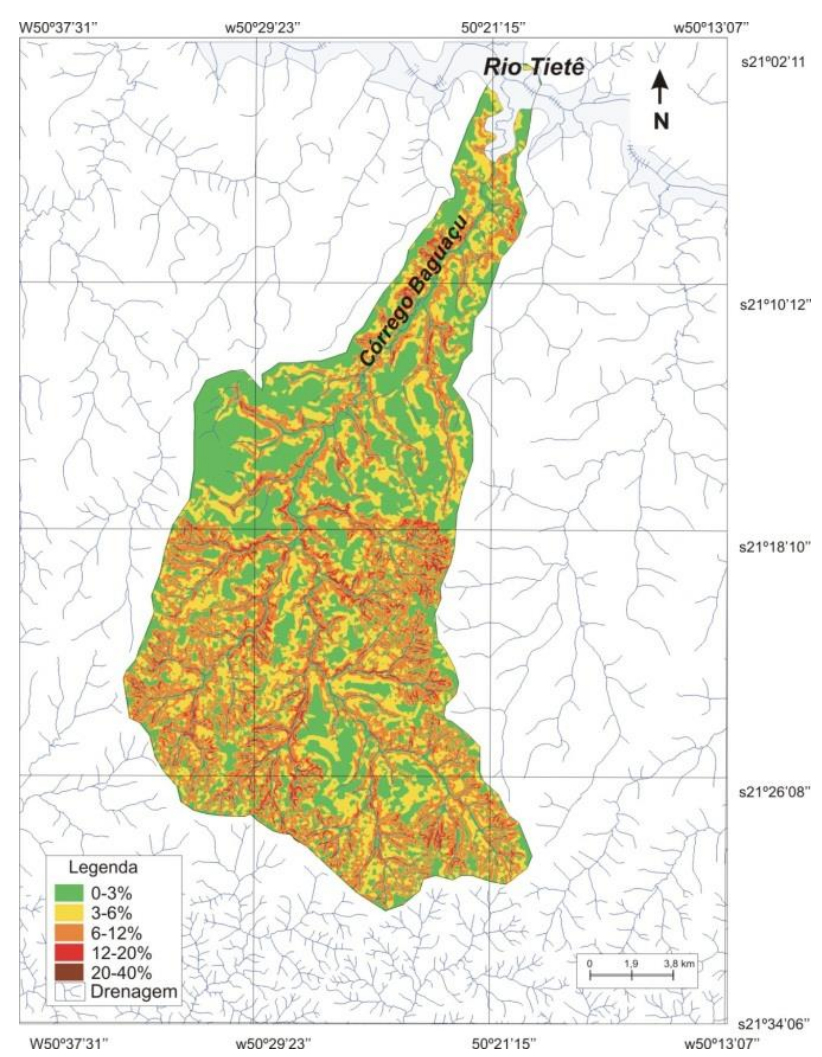

Figura 3: Mapa de declividade do Córrego Baguaçu. 


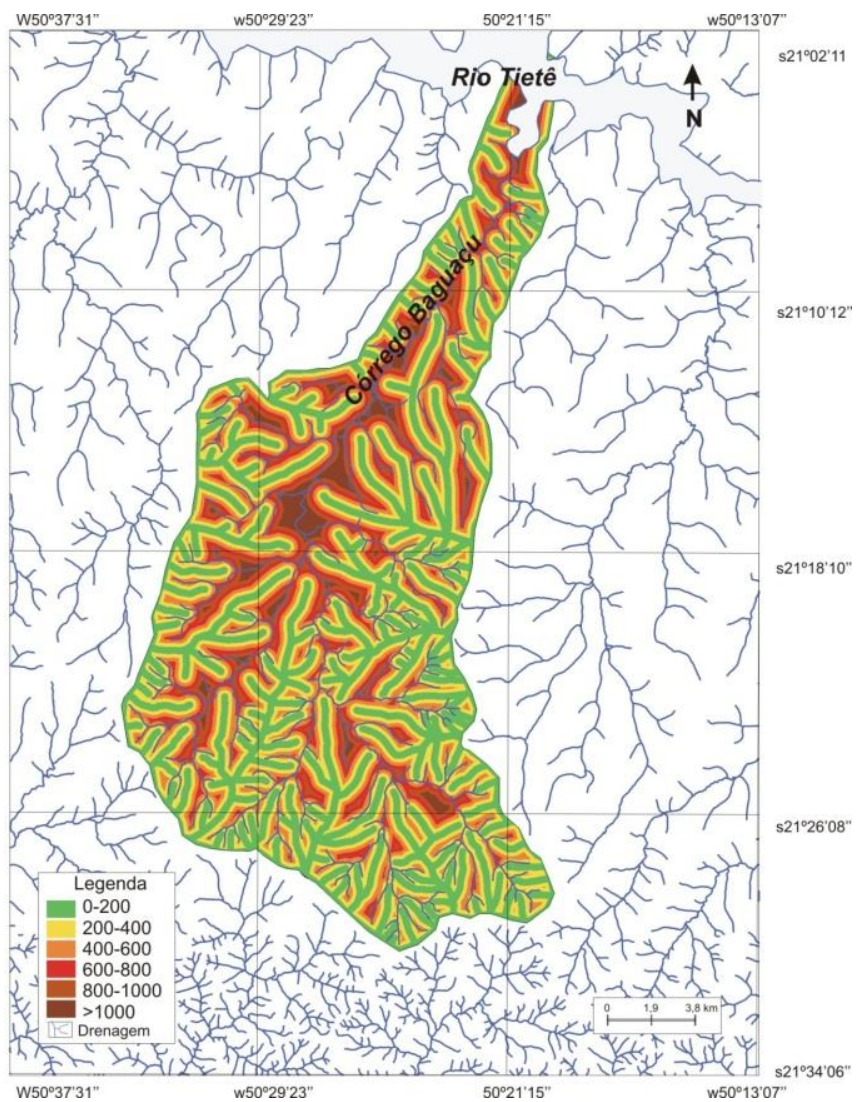

Figura 4: Mapa de Comprimento de rampa do Córrego Baguaçu

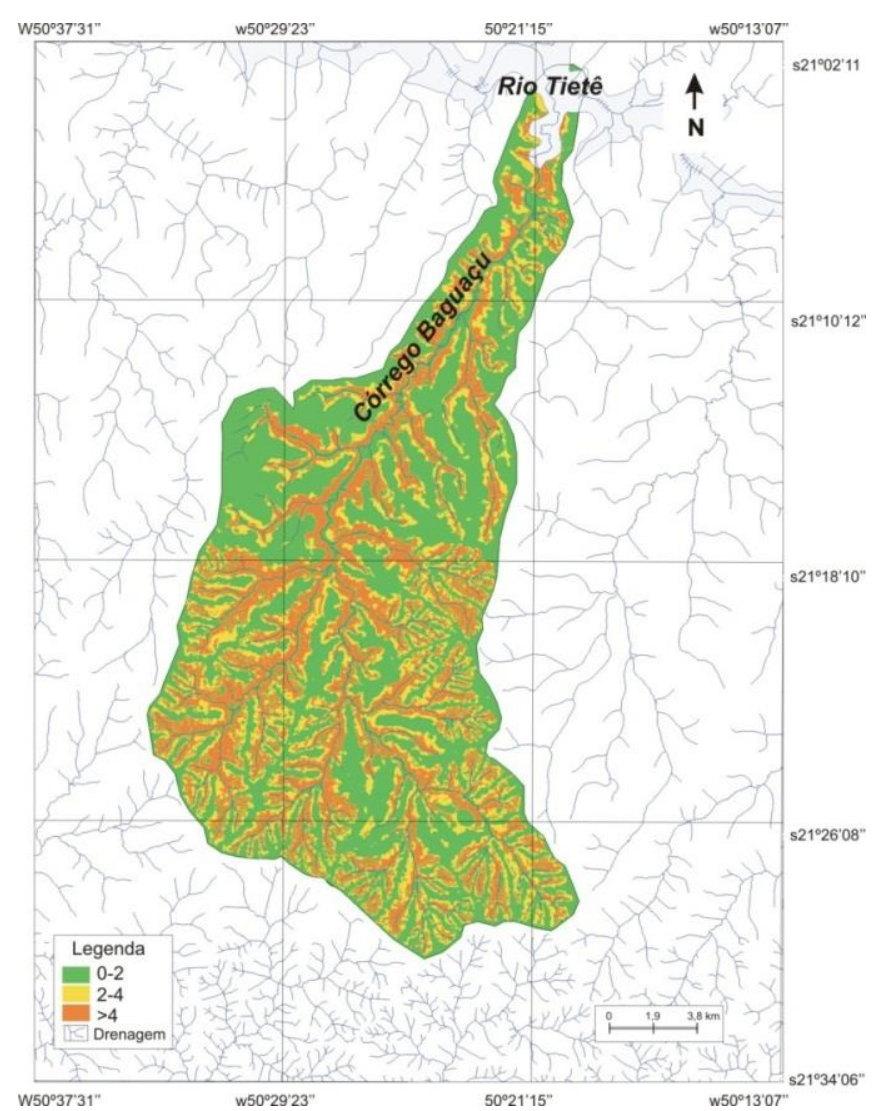

Figura 5: Mapa de fator topográfico do Córrego Baguaçu. 


\section{Uso e ocupação do solo e Fator C}

Os resultados mostraram que, para a cultura da cana-de-açúcar de ano em preparo convencional e a cana planta de ano e meio, o fator $\mathrm{C}$ é maior durante o primeiro ano de preparo convencional, diminuindo nos anos posteriores. A média do fator $\mathrm{C}$ para a cana de açúcar é de 0,0168 . O mesmo ocorre na pastagem do segundo ano em diante, onde os valores de Fator $\mathrm{C}$ são mais baixos, indicando maior eficiência da cobertura vegetal. A média do fator $\mathrm{C}$ para o pasto é de 0,0049 .

Para o milho apresentou resultado do Fator C mais elevado no período de crescimento e maturação da cultura, ou seja, é o período de menor proteção que a cultura oferece ao solo (Tabela 2). A média do fator C para o milho e soja, ou seja, cultura anual é de 0,1418 .

O plantio de eucalipto para celulose mostra que os valores tendem a diminuir do primeiro ano ao último, indicando que o eucalipto oferece boa proteção ao solo, minimizando os impactos da erosão.

O resultado do fator $\mathrm{C}$ do eucalipto para o Córrego Baguaçu de 0,000829 mostrou ser maior do que o utilizado por Vasquez-Fernandez et al. (1996), de 0,0001, porém mais baixo que o obtido por Martins (2005), de 0,0026. Na Figura 6 é mostrado o mapa de uso e ocupação do solo na bacia.

Tabela 2 - Fator C das principais culturas presentes na Bacia do Córrego Baguaçu.

\begin{tabular}{c|c|c|c|c|c|c|c}
\hline \multirow{2}{*}{$\begin{array}{c}\text { Estágios } \\
\text { de } \\
\text { desenvol- } \\
\text { vimento } \\
\text { da cultura }\end{array}$} & Pasto & Eucalipto & $\begin{array}{c}\text { Cana } \\
\text { planta } \\
\text { de ano }\end{array}$ & $\begin{array}{c}\text { Cana } \\
\text { planta } \\
\text { ano e } \\
\text { meio }\end{array}$ & $\begin{array}{c}\text { Estágios } \\
\text { de } \\
\text { desenvol- } \\
\text { vimento } \\
\text { da } \\
\text { cultura* }\end{array}$ & Milho & Soja \\
\hline $\mathbf{1}$ & 0,0402 & 0,000153 & 0,0447 & 0,0517 & $\mathbf{D}$ & 0,0091 & 0,0139 \\
\hline $\mathbf{2}$ & 0,0014 & 0,000471 & 0,0089 & 0,0120 & $\mathbf{P}$ & 0,0149 & 0,0235 \\
\hline $\mathbf{3}$ & 0,0014 & 0,000104 & 0,0089 & 0,0120 & $\mathbf{C}$ & 0,0170 & 0,0200 \\
\hline $\mathbf{4}$ & 0,0014 & 0,000046 & 0,0089 & 0,0120 & $\mathbf{M}$ & 0,0307 & 0,1535 \\
\hline $\mathbf{5}$ & 0,0014 & 0,0000010 & 0,0089 & 0,0120 & $\mathbf{C}$ & 0,003 & 0,0007 \\
\hline $\mathbf{6}$ & 0,0014 & 0,000001 & 0,0089 & 0,0120 & & - & - \\
\hline $\mathbf{7}$ & 0,0014 & 0,000024 & - & - & & - & - \\
\hline $\mathbf{8}$ & 0,0014 & 0,000021 & - & - & & - & - \\
\hline $\mathbf{9}$ & 0,0014 & - & - & - & & - & - \\
\hline $\mathbf{1 0}$ & 0,0014 & - & - & - & & - & - \\
\hline Fator C & 0,0049 & 0,000829 & 0,0149 & 0,0186 & & 0,0720 & 0,2116 \\
& (média) & (total) & (média) & (média) & & (total) & (total) \\
\hline
\end{tabular}

*Período de desenvolvimento, plantio e estabelecimento, crescimento e maturação e colheita.

\section{Fator P}

Aproximadamente 84,9\% dos solos da Bacia do Córrego Baguaçu possuem práticas conservacionistas de prática em contorno, ou seja, curvas de nível, e 15,1\% apresentam plantio morro abaixo, sendo áreas ocupadas, em sua maioria, por pastagens e declividades encontradas entre as classes de $0 \%$ a 10\%. Das áreas ocupadas por pastagens, lavouras de milho, soja e cana, grande parte delas oferece curvas de nível, sendo que as pastagens apresentam a maior área sem práticas conservacionistas (Figura 7). 


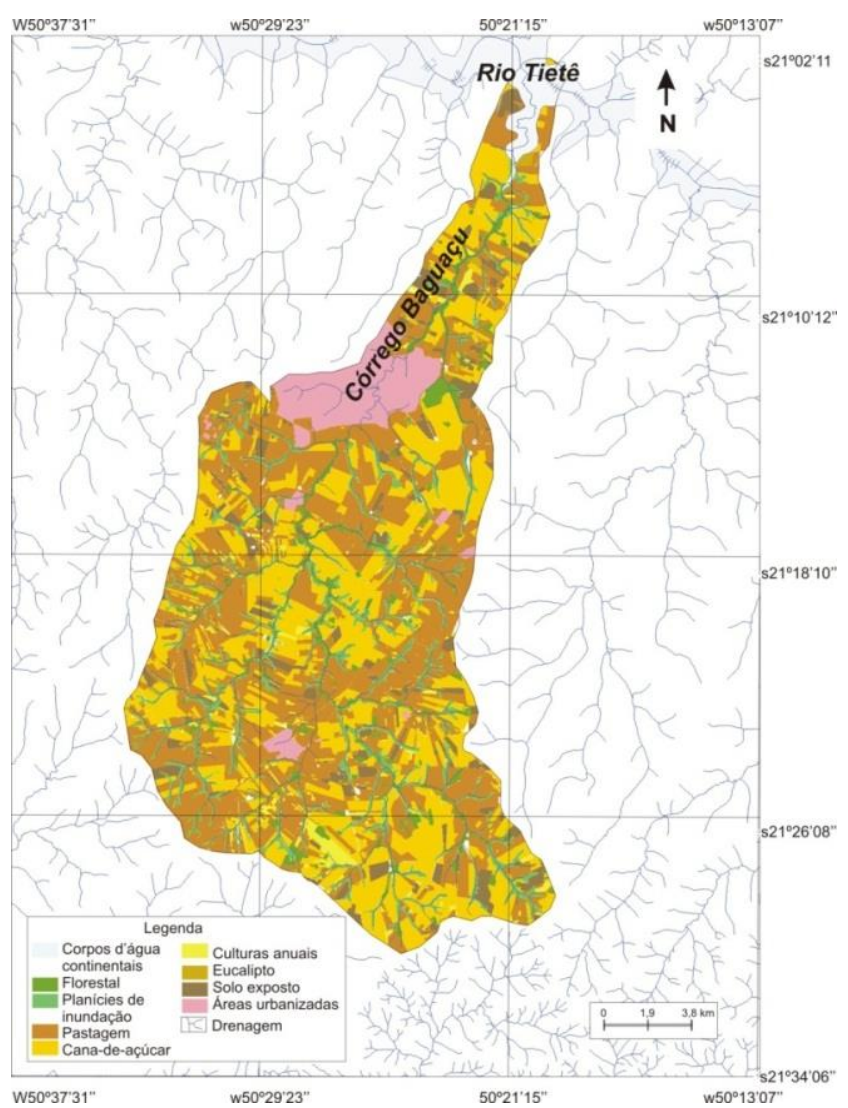

Figura 6: Uso e ocupação do solo na Bacia do Córrego Baguaçu.

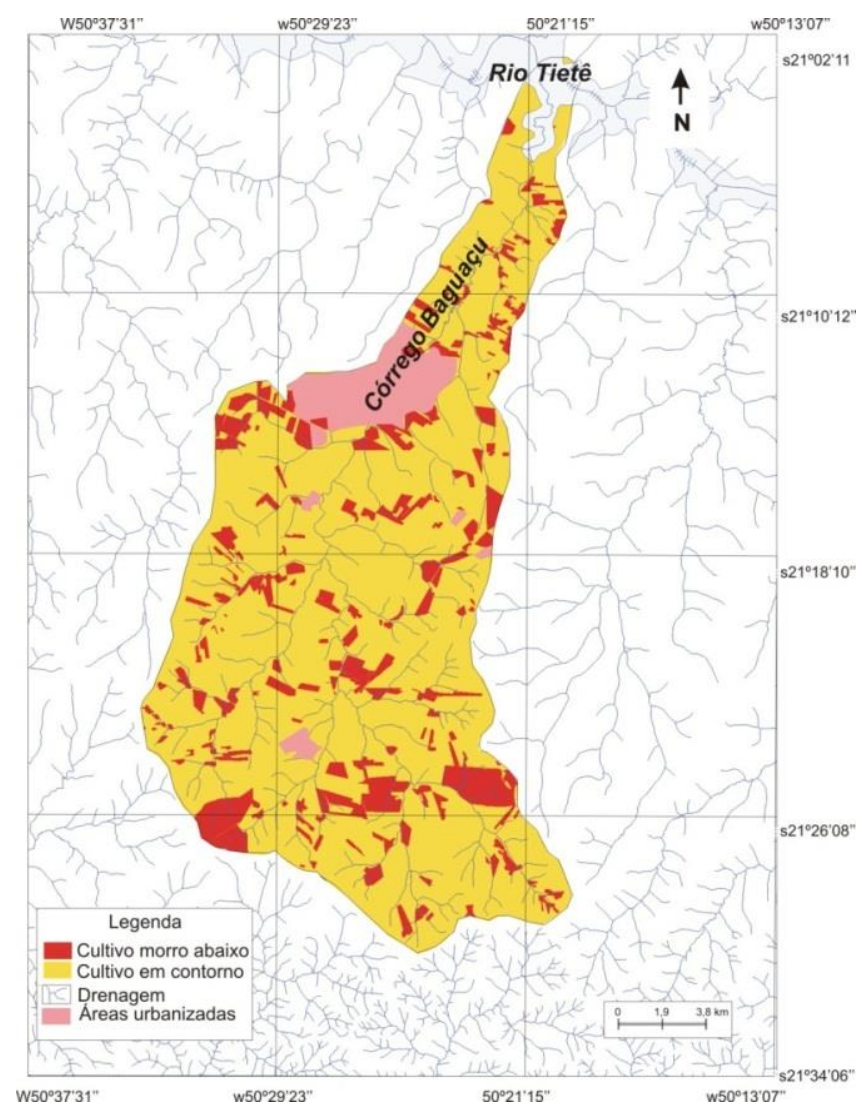

Figura 7: Fator P da Bacia do Córrego Baguaçu. 


\section{Equação Universal de Perda de Solos (EUPS)}

Utilizando a EUPS, equação, que relaciona os fatores naturais e antrópicos envolvidos no sistema da Bacia do Córrego Baguaçu, foi possível estimar a perda de solo por erosão laminar, indicando que a classe de maior perda de solo por erosão laminar para o ano de 2011 corresponde a de 0 a 3 toneladas por hectare ao ano (t/ha.ano), com 70,1\% da área da bacia. A mata, áreas de inundação e eucalipto, com menores valores de Fator C $(0,0004,0$ e 0,000829, respectivamente), estão exclusivamente inseridos na classe mais baixa de perda de solos, de 0 a $3 \mathrm{t} / \mathrm{ha}$.ano.

As perdas de solos por erosão de 0 a 3 t/ha.ano concentram-se nas porções mais altas das vertentes, áreas de interflúvios com topos aplainados; e no segmento da baixa vertente, próximas aos cursos d'água, onde a perda de solos é baixa ou quase nula, por serem áreas de deposição.

Nas declividades entre 3\% a 12\%, há maiores perdas de solos, variando desde 0 a 20 t/ha.ano. São áreas ocupadas, em sua maioria, por pastagem e cana, que, associadas a altas declividades e a erosividade das chuvas, principalmente entre os meses de outubro e março, nelas se acentuam o escoamento superficial e a remoção de sedimentos para as planícies de inundação. No alto curso da bacia, o caso ainda é agravado pela associação aos argissolos, pois são áreas que possuem tendência de remoção da camada superficial do solo pela enxurrada e dificuldades de infiltração da água, isso devido à diferenciação textural entre horizontes A e B textural.

A diminuição da permeabilidade dos solos é melhor visualizada à montante da bacia, nas cabeceiras de drenagem com maior dissecação do relevo, sob argissolos, que possuem maior densidade de drenagem devido às variações granulométricas da litologia do grupo Bauru, dificultando a infiltração (PEREZ FILHO, 1977 e TAVARES, 1986).

Nas classes que variam de 3 a 5 t/ha.ano há ocupação de pasto, predominantemente; a segunda ocupação é a de cana. Algumas áreas de culturas anuais e solo exposto estão presentes nas áreas com perdas de solos entre 5 a $>100$ t/ha.ano, devido ao maior valor de fator $\mathrm{C}$ para tais usos (Figura 8).

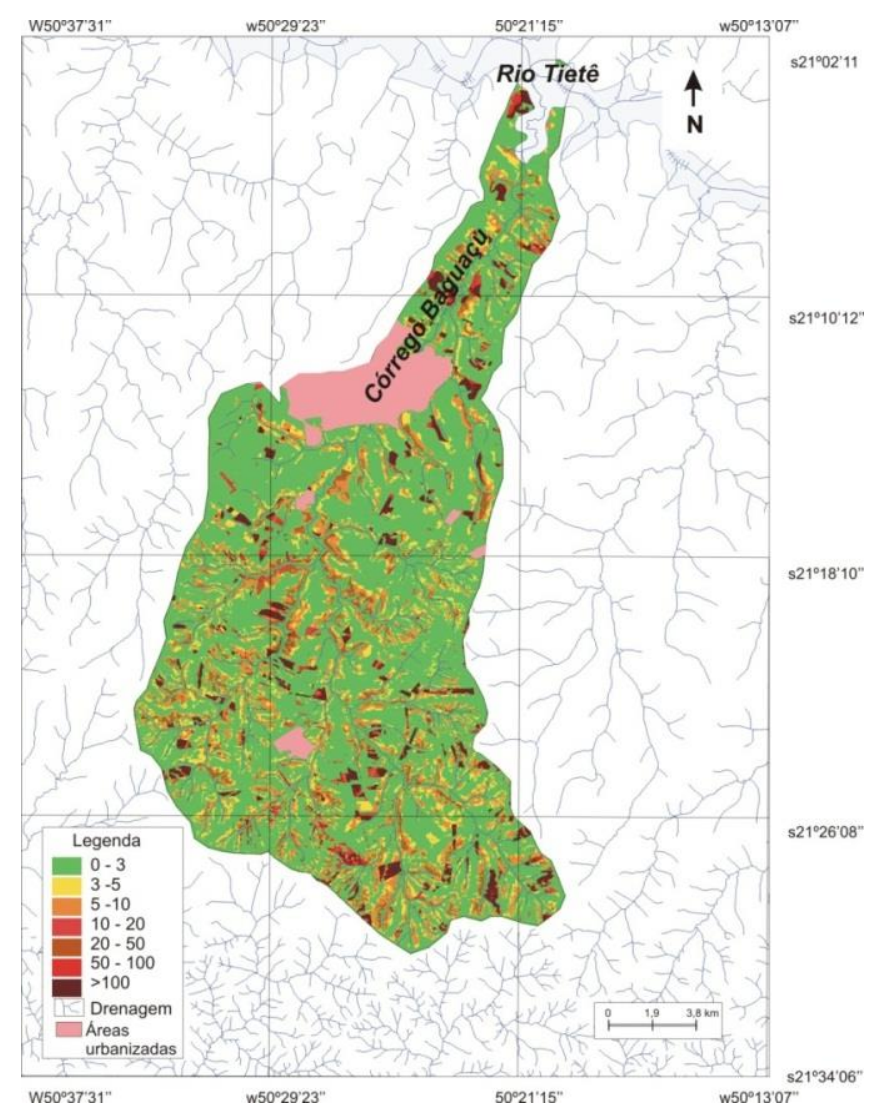

Figura 8: Perda de solos por erosão na Bacia do Córrego Baguaçu em 2011. 
Além do fator $\mathrm{C}$ do solo exposto, as áreas com plantio morro abaixo também é responsável pela perda de solo com mais de 100 t/ha.ano, por estarem distribuídas em declividades que variam, em sua maioria, nas classes de $0 \%$ a $3 \%$ e $6 \%$ a $12 \%$ de declividade.

O solo exposto foi classificado com alto potencial de erosão laminar, isso devido à falta de cobertura vegetal, lembrando que a maioria das áreas com solo exposto são áreas que estão sendo preparadas para o plantio, provavelmente para cana.

Se considerarmos que a pastagem ocupa $41,4 \%$ da bacia, com $9,4 \%$ de ocupação pouco adequada e $32 \%$ de área de ocupação adequada, enquanto que a cana-de-açúcar ocupa $31,4 \%$ da bacia e $12,1 \%$ da ocupação é considerada pouco adequada e 19,3\% adequada, pode-se concluir que a cana produz maior carga de sedimentos erosivos se comparada à pastagem. Porém, quando relacionamos o uso às perdas de solos (EUPS), é possível ver que a cana e a pastagem são eficientes na proteção do solo, mantendo a perda de solos por erosão laminar nas classes mais baixas, entre 0 a 3 t/ha.ano (Tabela 3).

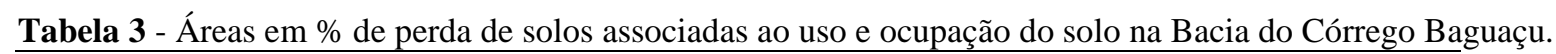

\begin{tabular}{|c|c|c|c|c|c|c|c|}
\hline \multirow{2}{*}{ Classes de uso } & \multicolumn{7}{|c|}{$\%$ de perda de solo em t/ha.ano } \\
\hline & $0-3$ & $3-5$ & $5-10$ & $10-20$ & $20-50$ & $50-100$ & $>100$ \\
\hline Corpos d'água continentais & 0,9 & 0 & 0 & 0 & 0 & 0 & 0 \\
\hline Florestal & 5,2 & 0 & 0 & 0 & 0 & 0 & 0 \\
\hline $\begin{array}{l}\text { Planícies de } \\
\text { inundação }\end{array}$ & 6,9 & 0 & 0 & 0 & 0 & 0 & 0 \\
\hline Pastagem & 33,6 & 5,1 & 2,4 & 0,3 & 0 & 0 & 0 \\
\hline Cana-de-açúcar & 16,5 & 4,7 & 6,8 & 3,0 & 0,4 & 0 & 0 \\
\hline Culturas anuais & 0,4 & 0 & 0,1 & 0,2 & 0,5 & 0,5 & 0,2 \\
\hline Eucalipto & 0,3 & 0 & 0 & 0 & 0 & 0 & 0 \\
\hline Solo exposto & 1,3 & 0 & 0 & 0,1 & 0,4 & 0,6 & 3,6 \\
\hline Áreas urbanizadas & 5,8 & 0 & 0 & 0 & 0 & 0 & 0 \\
\hline
\end{tabular}

Por serem predominantes na bacia, o pasto e a cana também são as classes que representam maior adequação em relação à expectativa de maior erosão laminar em função dos fatores antrópicos, porém Stein et al. (1987) chamam a atenção para o fato de que, mesmo em áreas de discrepância negativa ou nula, pode haver processos erosivos devido à cobertura precária do terreno, como em pastos e em culturas temporárias e perenes. As culturas anuais (milho e soja) representam apenas $11,7 \%$ de área da bacia e apresentaram perdas de solo nas classes mais altas consideradas neste estudo, indicando uma perda de $2 \%$ do total de perda de solos.

Os resultados da EUPS mostram que em relação ao limite tolerado de perda de solos para o Argissolo e para o Latossolo, grande parte de área ocupada pela bacia está abaixo da tolerância considerada. Quando considerado que o Argissolo, de acordo com Bertoni e Lombardi Neto (2012), possui tolerância de 4,5 t/ha, cerca de $35 \%$ do uso ocupado no argissolos possui perda de solos abaixo da sua perda permissível e para o Latossolo Vermelho, que possui maior limite de tolerância, 15 t/ha, aproximadamente 39,3\% de sua área corresponde a perdas na classe mais baixa, de 0 a 3 t/ha.ano.

\section{CONCLUSÕES}

Apesar das críticas a modelos empíricos de estimativas de perdas de solos por erosão, como a EUPS, o resultado aplicado na Bacia do Córrego Baguaçu mostrou-se satisfatório diante dos objetivos e das hipóteses propostos no início do trabalho.

De uso relativamente fácil, é resultado da interação de variáveis físicas e antrópicas, que possibilitam a identificação de áreas com menor e maior vulnerabilidade aos processos erosivos, indicando os possíveis fatores relacionados a tais eventos. O modelo ainda permitiu a indicação de algumas melhorias que visem planejamentos futuros, de forma a minimizar os impactos relacionados aos processos erosivos agrícolas. Vale frisar que o resultado de tal modelo é uma estimativa e seu uso só prediz erosão de origem laminar, excluindo formas de erosão mais avançadas. 
A estimativa de perda de solos por erosão na Bacia do Córrego Baguaçu concentra-se em 0 a 3 t/ha.ano, ou seja, a expectativa de erosão é baixa, porém esses resultados foram encontrados, em grande parte, em planícies de inundação, que são áreas de deposição de sedimentos, e em áreas com cultivo de eucalipto e vegetação nativa. Áreas com maiores perdas de solos estão, na maioria, nas médias encostas de relevo de colinas médias e declividades maiores, associados aos argissolos provenientes das camadas espessas de arenitos finos da formação Adamantina do Grupo Bauru.

O papel do uso do solo e as práticas conservacionistas da EUPS são elementos decisivos, que atenuaram significadamente as perdas de solo resultado das condições intrínsecas da Bacia do Córrego Baguaçu, resultado que reforça a importância do uso e de práticas adequadas para minimizar as perdas de solo por erosão.

\section{AGRADECIMENTOS}

Agradecemos a Coordenação de Aperfeiçoamento de Pessoal de Nível Superior (CAPES) pela concessão da bolsa de estudos ao primeiro autor.

\section{REFERÊNCIAS}

BERTONI, J.; LOMBARDI NETO, F. Conservação do solo. 8. ed. São Paulo: Ícone, 2012.

BOIN, M. R. Chuvas e erosões no Oeste Paulista: uma análise climatológica aplicada. $2000281 \mathrm{f}$. Tese (Doutorado em Geociências). IGCE, Universidade Estadual Paulista. Rio Claro.

CARVALHO, M. de P. Predição de perda de terra por erosão na lavoura canavieira paulista. Disponível em: <http://www.feis.unesp.br/Home/depar tamentos/fitossanidadeengenhariaruralesolos715/erosao-cana.pdf>. UNESP, 2012. Acesso em: 13 out. 2014.

CETEC. Centro Tecnológico da Fundação Paulista de Tecnologia e Educação. CBH-BT Comitê da Bacia Hidrográfica do Baixo Tietê. Plano de Bacia do Baixo Tietê. Relatório Final, 1999.

COELHO, A. P. Fator erosividade da chuva de Votuporanga (SP). Ilha Solteira, 2001, 101p. Dissertação (Mestrado em Agronomia)- Faculdade de Engenharia de Ilha Solteira, Universidade Estadual Paulista UNESP.

DEMARCHI, J. C. Geotecnologias aplicadas à estimativa de perdas de solo por erosão hídrica na SubBacia do Ribeirão das Perobas, município de Santa Cruz do Rio Pardo - SP. 2012. 167 f. Dissertação (Mestrado em Agronomia). Faculdade de Ciências Agronômicas da Unesp - Câmpus de Botucatu. Botucatu, SP.

EMPLASA, Empresa Paulista de Planejamento Metropolitano S/A. Imagens ortorretificadas, Resolução 1 m. zona 22 e 23. 2010/2011.

FOSTER, G. R. et. al. (1981). Conversion of the Universal Soil Loss Equation to SI metric units. Journal of Soil and Water Conservation. Vol. 36, n. 6, p. 355-359.

IBGE. Instituto Brasileiro de Geografia e Estatísticas. IBGE Cidades: Fonte IBGE, Produção Agrícola Municipal, 2011. Rio de Janeiro: IBGE, 2012. Disponível em: <www.ibge.gov.br/cidadesat/index.php>. Acesso em: 5 ago. 2013.

LEPSCH, I. F. 19 lições de pedologia. São Paulo: Oficina de Textos, 2011.

LOMBARDI NETO, F.; MOLDENHAUER, W. C. Erosividade da chuva: sua distribuição e relação com perdas de solo em Campinas, SP. Bragantia, v. 51, p. 189-196, 1992.

MARDEGAN, C. M. A ocorrência de espécies de cerrado em 18 fragmentos com fisionomia florestal no noroeste do estado de São Paulo e as características do solo. 91f. 2012. Tese (Doutorado em Ciências Biológicas). Universidade Estadual Paulista. Botucatu, SP.

MARTINS, S. G. Erosão hídrica em povoamento de eucalipto sobre solos coesos nos tabuleiros costeiros, ES. 2005. 117f. Tese (Doutorado em Agronomia) Universidade Federal de Lavras. Minas Gerais. 
MITASOVA, H. et al. GIS tools for erosion/deposition modeling and multidimensional visualization. Part V: Impact of transport capacity and terrain structures on erosion simulations. 1997. Geographic Modeling and Systems Laboratory, University of Illinois at Urbana-Champaign, Urbana, Illinois. Disponível em: <http://www4.ncsu.edu/ hmitaso/gmslab/reports/ cerl97/rep97.html>. Acesso em: 6 maio 2015.

OLIVEIRA, J. B. Solos do Estado de São Paulo: descrição das classes registradas no mapa pedológico. Campinas, Instituto Agronômico, 1999. 108p.

PEREZ FILHO, A. Análise estrutural da Bacia do São José dos Dourados (SP). 1977. 122 f. Dissertação (Mestrado em geomorfologia) - Faculdade de Filosofia Ciências e Letras Humanas, Universidade de São Paulo, São Paulo.

PRUSKI, F. F. Conservação do solo e água: práticas mecânicas para o controle da erosão hídrica. 2. ed. Viçosa, MG: Ed. UFV, 2009. 279 p.

ROSS, J. L. S. Ecogeografia do Brasil: subsídios para planejamento ambiental. São Paulo: Oficina de Textos, 2006. 208 p.

ROQUE, C. G.; CARVAlHO, M. P.; PRADO, R. M. Fator erosividade da chuva de Piraju (SP): distribuição, probabilidade de ocorrência, período de retorno e correlação com o coeficiente de chuva. RBCiS, v. 25, p. 147-154, 2001.

RUTHES, J. M. et al. Uso de sistema de informação geográfica na determinação do fator topográfico da Bacia do Rio Catorze, Sudoeste do PR. Revista Brasileira de Geografia Física. Pernambuco. 05 (2012) 1099-1109.

SOUZA, W. de. Estimativa de perdas de solo por erosão laminar na bacia do Córrego Pinhalzinho II com suporte de geoprocessamento. 2010 . 75 f. Dissertação (Mestrado em Geografia). Universidade Estadual de Maringá -UEM. Maringá, PR.

STEIN, D. P. et al. Potencial de erosão laminar, natural e antrópico, na Bacia do Peixe-Paranapanema. Anais Simpósio Nacional de Controle de Erosão, 4. Marília, SP. Fev. 1987, p. 105-135.

SUDO, H. A problemática da erosão em solos derivados do arenito Bauru na região extremo oeste do estado de São Paulo. Anais Simpósio sobre controle de erosão, São Paulo, v. 2,p. 185-194, 1981.

SUGUIMOTO, E. I. A expansão da cana em Birigui e a dinâmica agrária regional. 2011. 135 f. Dissertação (Mestrado em Geografia). Universidade Federal do Mato Grosso do Sul. Três Lagoas, MS.

TAVARES. A. C. A erosão dos solos no contexto da análise ambiental: o exemplo do alto curso do Rio São José dos Dourados. 1986. 254 f. Tese (Doutorado em Geografia). Faculdade de Filosofia, Letras e Ciências Humanas. Universidade de São Paulo. São Paulo.

TOMAZONI, J. C.; GUIMARÃES, E. A sistematização dos fatores da EUPS em SIG para quantificação da erosão laminar na Bacia do Rio Jirau. RBC - Revista Brasileira de Cartografia. $N^{\circ}$ 57/03, p. 1-10 e p. 236, 2005.

VASQUEZ-FERNÁNDEZ, G. A. et al. Determinação de sequências culturais em microbacia hidrográfica para caracterização do Fator C da EUPS, utilizando fotografia aérea. Anais VIII Simpósio Brasileiro de Sensoriamento Remoto, Salvador, Brasil, 14-19 abril 1996, INPE, p. 63-67.

WISCHMEIER, W. H.; SMITH, D. D. Predicting rainfall erosion losses - a guide to conservation planning. Washington, D.C.: USDA, 1978. 58 p. (Agriculture Handbook, 537). 